\title{
GPs and involuntary admission: a qualitative study
}

\author{
Britta Jepsen, Kirsten Lomborg and Marianne Engberg
}

\author{
ABSTRACT \\ Background \\ In many countries, medical authorities are responsible \\ for involuntary admissions of mentally ill patients. \\ Nonetheless, very little is known about GPs' \\ experiences with involuntary admission. \\ Aim \\ The aim of the present study was to explore GP's \\ experiences from participating in involuntary \\ admissions. \\ Setting \\ General practice, Aarhus, Denmark. \\ Method \\ One focus group interview and six individual interviews \\ were conducted with 13 Danish GPs, who had recently \\ sectioned one of their own patients. \\ Results \\ GPs experienced stress and found the admission \\ procedure time consuming. They felt that sectioning \\ patients was unpleasant, and felt nervous, but \\ experienced relief and professional satisfaction if things \\ went well. The GPs experienced the doctor-patient \\ relationship to be at risk, but also reported that it could \\ be improved. GPs felt that they were not taken \\ seriously by the psychiatric system. \\ Conclusion \\ The unpleasant experiences and induced feelings \\ resulting from involuntary admissions reflect an \\ undesirable and stressful working environment. \\ Keywords \\ coercion; commitment of mentally ill; doctor-patient \\ relations; general practice; psychiatry; qualitative \\ research.
}

B Jepsen, MD, School of Public Health, Department of General Practice; K Lomborg, MSN, PhD, associate professor, School of Public Health, Department of Nursing Science, Aarhus University, Denmark; M Engberg, MD, PhD, psychiatrist, associate professor, School of Public Health, Department of General Practice, Aarhus University, Denmark and Rehabilitation and Research Centre for Torture Victims, Copenhagen, Denmark.

Address for correspondence

Dr Britta Jepsen, Rouloen 39, 8250 Egaa, Denmark.

E-mail: britta.jepsen@alm.au.dk

Submitted: 31 July 2009; Editor's response: 13 October 2009; final acceptance: 22 January 2010.

(C)British Journal of General Practice 2010; 60: 604-606.

DOI: 10.3399/bjgp10X515115

\section{INTRODUCTION}

Legislation governing involuntary psychiatric admission (sectioning) differs between European countries. ${ }^{1-3}$ In Denmark, physicians have the authority to decide whether to section an individual. The police participate to provide practical assistance and ensure that the law is correctly enforced. No other professionals are required. After arrival at the psychiatric institution, the consultant psychiatrist must evaluate whether the indications for sectioning the patient are fulfilled, before the patient is taken to the department. The main regulations according to the Danish Mental Health Act are summarised in Box 1.4-6

Very little evidence exists on the GPs' participation in involuntary admissions, although it has implications for serious issues, such as the use of coercion in society, legal and human rights, treatment of the most severely mentally ill patients, patient-doctor relationships, and the working environment for the GPs themselves. The aim of the present study was to explore GP's experiences from participating in involuntary admissions.

\section{METHOD}

All GPs who had sectioned one of their registered patients to the psychiatric hospital in Aarhus, Denmark, between 1 May and 31 August 2006 were included. A focus group interview with seven GPs and six individual interviews were carried, with one interviewer and one observer.

The transcribed interviews were labelled and systematised into categories that appeared when reading through the text. The text in each category was subsequently condensed and the entire material interpreted according to qualitative descriptive analysis..$^{7-10}$ The analysis was performed by the interviewer and the observer.

\section{RESULTS}

Forty-one certificates were collected. Thirty-three of the involuntary admissions were performed by GPs. Of these, 14 were GPs admitting one of their 'own' patients, 13 of whom agreed to participate.

\section{Experiences relating to the admission procedure}

The GPs found the involuntary admission stressful 
because of the uncertainty about what was going to happen. They also found the procedure time consuming, including waiting for the police to arrive, the effort of finding and helping the patient, and dialogues with the patient, the relatives, and the staff at the psychiatric hospital.

The GPs found these consultations very different from normal consultations because they were initiated by the doctor, and because the patients were often so upset that it was difficult for them to carry out a conversation.

\section{Experiences relating to the patient and the GP themselves}

The GPs felt it was unpleasant because it touched them deeply to see the patients constrained. They were also nervous to varying degrees because of the stressful situation, and potentially aggressive patients; they had received verbal assaults and threats, but were more seldom exposed to physical violence:

'She threatened me that one day she would stab me with a knife ... It affected me a lot. I guess I have realised, she won't do it, but suddenly things can happen ...'

'I feel like I am skating on thin ice, because I don't do involuntary admissions that often.'

The GPs felt professional satisfaction when administering the necessary help to the patient and were relieved if things went well:

'Maybe it is weird, but when the patient is picked up by the police and taken away, I feel happy. Maybe it is a bit strange, but I get some kind of feeling that I have handled the situation correctly.'

Some GPs were frustrated because they had repeatedly admitted a patient who never seemed to benefit from the admissions. They felt despondent during these admissions, and that the sectioning was even more restrictive for the patient:

' get disillusioned ... you keep admitting them involuntarily again and again. They get treated and feel better. Then they get discharged and stop taking their medicine, and get worse. Somehow I think it is humiliating to keep on admitting them involuntarily.'

The experiences from involuntary admissions were not easily forgotten, and the GPs found it important to share them with others.

\section{How this fits in}

This is the first study to report GPs' experiences of participation in involuntary admissions. The study showed that GPs experienced involuntary admissions as unpleasant, stressful, and time consuming; they felt that the psychiatric system did not take them seriously; but they felt professional satisfaction when administering the patient the help that was needed and handling the situation correctly.

\section{Experiences relating to the doctor-patient relationship}

The GPs believed that the sectioning could have a negative effect on the doctor-patient relationship. In some cases, the patient would later request another GP in the healthcare centre, or change GP altogether. Some GPs believed that, because they had helped the patient in a difficult situation, their relationship would grow stronger:

'The patient is still a patient in our practice, but he prefers to see the other doctors, and I understand why ...'

'I got to know the patient better, because I have seen her in such an extreme situation.'

Some GPs stated that, on a professional level, it was easier to section their own patients because they were familiar with the patients' history and habitual mental state. The potential risk of harming the doctor-patient relationship made it more complicated to admit their own patients, although it did not prevent any GPs from doing so:

I think twice when it is my own patient: "Is it wise?" ... I would be sorry, if the patient registers with another GP because of this.'

\section{Box 1. Main regulations of the Danish Mental Health Act in relation to involuntary admissions. ${ }^{4-6}$}

- If a person, likely to be insane, does not seek necessary care, a physician must be alerted. Based on an examination of the patient and the available information, the physician evaluates whether admission to a psychiatric institution is required. If so, and the patient opposes admission, the physician determines whether involuntary admission is required.

- The physician must section the patient if the criteria for involuntary admission are fulfilled. Involuntary admission may only take place if the patient is psychotic or in a similar condition, and it would be irresponsible not to admit the patient for treatment as (a) the chance of a substantial improvement of the patient's condition otherwise would be substantially decreased, or (b) the patient poses an immediate and substantial danger to himself or herself or others.

- The physician must certify, in writing, that the criteria are fulfilled.

- The police ensure that the law is correctly enforced, and transport the patient to the psychiatric institution.

- After arrival at the psychiatric institution, the consultant psychiatrist must confirm that the criteria for involuntary admission are fulfilled, before sectioning can take place. 


\section{Experiences relating to the psychiatric healthcare system}

Some GPs felt that the psychiatric system did not take them seriously. For instance, some GPs spent a lot of time on bureaucracy when they called the psychiatrist in charge at the psychiatric hospital to announce that the patient was coming, because they sensed the psychiatrists' reluctance to receive the patients. Patients were often discharged within a few days without any changes in medication or treatment. The GPs felt that in doing so, the psychiatric system did not acknowledge how problematic it was getting the patient into the hospital. They felt that the psychiatric system did not take adequate responsibility for psychiatric treatment, due to financial difficulties:

'It is totally unfair that we spend a quarter of a working day on bureaucracy. In my case I was redirected on the telephone four to five times without reaching a competent specialist.'

'In my opinion, the psychiatric hospital is like a lot of other departments: they want to keep the patients away from their doorstep.'

'I feel we are like rubbish bins for all of it, right?'

\section{DISCUSSION}

\section{Summary of main findings}

This is the first study to report GPs' experiences of sectioning their own patients. The high participation rate indicated that the issue was important to the GPs. The unpleasant experiences and induced feelings reflect an undesirable and stressful working environment during involuntary admission.

\section{Strengths and limitations of the study}

An explorative qualitative approach was chosen because no previous evidence exists in the field. Both focus group interview and individual interviews were carried out because it was hypothesised that emotional and problematic experiences would be difficult for the GPs to expose in a group. However, this was not the case; on the contrary, the GPs in the focus group spoke very explicitly about their feelings and difficulties, as did the GPs during the individual interviews.

GPs' experiences are likely to be the same in other countries, although differences in legislation and procedures may reduce the generalisability of this study's findings.

Methodological issues appear when doctors interview doctors. As an insider, the interviewer can possibly gain rich insight by capitalising on a shared culture. On the other hand, a need to project a positive professional identity may influence the informants' responses. ${ }^{11}$ However, the observer, who also took part in the analysis, is a nurse. Having an outsider involved in the interpretation of the data compensates the drawbacks of either approach. ${ }^{11}$

\section{Comparison with existing literature}

Dealing with involuntary admissions is a rare activity, which to some extent has similarities with requests for euthanasia. Both activities are unpleasant challenges connected with feelings such as discomfort, frustration, and uncertainty. ${ }^{12,13}$

\section{Implications for clinical practice}

Efforts to improve these working conditions and to facilitate the admission process - among others the collaboration with the psychiatric institution - should be prioritised, not only to improve conditions for the GP, but also to secure the proper treatment of patients.

\section{Funding body}

Funding was provided by the Danish Research Foundation for General Practice (05/4593).

\section{Competing interests}

The authors have stated that there are none.

\section{Acknowledgements}

We would like to thank chief psychiatrist Ulla Bartels and the staff at the Emergency Department, Psychiatric Hospital in Aarhus, for cooperation.

\section{Discuss this article}

Contribute and read comments about this article on the Discussion Forum: http://www.rcgp.org.uk/bjgp-discuss

\section{REFERENCES}

1. Dressing H, Salize H, Gordon H. Legal frameworks and key concepts regulating diversion and treatment of mentally disordered offenders in European Union member states. Eur Psychiatry 2007; 22(7): 1-6.

2. Salize H, Dressing H. Epidemiology of involuntary placement of mentally ill people across the European Union. Br J Psychiatry 2004; 184: 163-168.

3. Salize H, Dressing H. Compulsory admission of mentally ill patients in European Union Member States. Soc Psychiatry Psychiatr Epidemiol 2004; 39(10): 797-803.

4. Bekendtgørelse af lov om anvendelse af tvang i psykiatrien. LBK nr 111 01/11/2006 [Ministerial order of law on use of coercion within psychiatry.] https://www.retsinformation.dk/Forms/R0710.aspx?id=10339 (accessed 29 Jun 2010).

5. Bekendtgørelse om fremgangsmåden ved gennemførelse af tvangsindlaeggelser BEK nr 1498 af 14/12/2006. [Ministerial order on the procedure for involuntary admission. https://www.retsinformation.dk/Forms/R0710.aspx?id=11037 (accessed 29 jun 2010).

6. Sestoft D, Engberg M. Law and mental health in Denmark. Int J Law Psychiatry 2000; 23(5-6): 533-540.

7. Kvale S. Interviews: an introduction to qualitative research interviewing. Thousands Oaks: Sage, 1996

8. Maltherud K. Kvalitative metoder i medisinsk forskning (2. utgave). [Qualitative methods in medical research (2nd edn)]. Oslo: Universitetsforlaget, 2003.

9. Sandelowski M. Whatever happened to qualitative description? Res Nurs Health 2000; 23(4): 334-340.

10. Krueger R, Casey M. Focus groups. 3rd edn. Thousand Oaks: Sage, 2000

11. Coar L, Sim J. Interviewing one's peers: methodological issues in a study of health professionals. Scand J Prim Health Care 2006; 24(4): 251-256.

12. Georges JJ, The AM, Onwuteaka-Philipsen BD, et al. Dealing with request for euthanasia: a qualitative study investigating the experience of general practitioners. J Med Ethics 2008; 34(3): 150-155.

13. Deschepper R, Vander Stichele R, Bernheim JL, et al. Communication on end-of-life decisions with patients wishing to die at home: the making of guidelines for GPs in Flanders, Belgium. Br J Gen Pract 2006; 56(522): $14-19$ 